\title{
Interculturalidad para una pedagogía urbana
}

\section{Joyce Sánchez Espinoza*}

Esta ponencia trata de los intentos de descolonizar la mente del ciudadano ecuatoriano del mundo hispano, o el ecuatoriano mestizo, pues considero firmemente que la descolonización no es un proceso que únicamente debe experimentar la población indígena de Ecuador. El proceso de descolonización debe iniciarse también en la población hegemónica, la hispano mestiza ecuatoriana, para que pueda existir un dialogo franco, solidario y constructivo nacional. La interculturalidad no es posesión, ni propiedad, ni de uso exclusivo de algún grupo étnico o socioeconómico. La interculturalidad es para todos, también para los mestizos de Ecuador. Es más, yo diría que hasta ahora muchos de los diálogos sostenidos entre indígenas y mestizos, afroecuatorianos y mestizos, no genera mucho fruto y sigue marginalizado este encuentro porque, precisamente, la población mestiza o hispana ecuatoriana no está educada en los principios de la interculturalidad. Recordemos pues, que la interculturalidad no es folklorismo.

\section{Antecedentes}

Desde el inicio de mis estudios en la materia de Interculturalidad, en el año 2000 hasta el actual momento, lo que he observado es que la existencia de un organismo como la DINEIB (Dirección Nacional de Educación Intercultural Bilingüe) parece no ser suficiente para consolidar una identidad nacional en el ciudadano ecuatoriano, puesto que esta institución ha mantenido, hasta ahora, su circuito de acción en las esferas netamente indígenas. De tal manera que lo que se nota es que la población mestiza se ha quedado huérfana de estos procesos formativos $\mathrm{y}$, por lo tanto, he visto necesario acercar la interculturalidad a la Educación Hispana ecuatoriana y trabajar la interculturalidad para el mundo mestizo ecuatoriano en mi investigación. Confiando, además, en los esfuerzos

\footnotetext{
* $\quad$ Ponencia presentada en el V Encuentro de Estudios Ecuatorianos LASA / Ecuador, Quito, 2011.

** Coordinadora del Observatorio Intercultural del Ecuador. Directora Ludoteca Intercultural. Email: joycesanchezespinoza@yahoo.com.
} 
que concentra la DINEIB en la Educación Intercultural de todo el territorio ecuatoriano, a través de sus direcciones provinciales, he considerado oportuno dedicar mi investigación específicamente a las zonas rurales y urbanas de la Educación Hispana.

La reforma curricular ecuatoriana contempla la interculturalidad como eje transversal para la Educación Hispana siendo coherente y como una aportación a la condición histórica y antropológica reconocida constitucionalmente en nuestro país como uno, pluricultural e intercultural mas sin haber desarrollado ciertos aspectos importantes de la materia que ayudarían a los docentes de la Educación Hispana a trabajar con ella en el aula, tales como son: contenidos y metodología de la Interculturalidad.

La interculturalidad desde mi investigación y, a través de Ludoteca como proyecto de Pedagogía urbana, se enfoca desde la Filosofía de la Educación distinguiendo elementos como la ontología, teleología, axiología y deontología de esta disponiendo dichos contenidos didácticamente ante los ciudadanoslectores para que trabajen con ellos, específicamente para los docentes de la Educación Hispana ecuatoriana.

La exclusión de un programa educativo y un currículo para la Educación Hispana que aborde y maneje la identidad ecuatoriana pluricultural ha traído consigo la postergación y aletargamiento del desarrollo de una identidad nacional más sólida. La necesidad de la Pedagogía Intercultural es eminentemente necesaria en una época en la cual, finalmente, Ecuador empieza a reconocerse como nación. Un país que se declara pluricultural necesita de un mecanismo, el dossier intercultural, para viabilizar su diversidad en su colectivo, pues la interculturalidad es el "dialogo en sí mismo de identidades".

\section{Proyecto intercultural de la ludoteca}

El proyecto Ludoteca consiste en ser y estar como un espacio dedicado a la investigación y a la práctica pedagógica de la Interculturalidad estableciendo una didáctica social para prácticas de una pedagogía intercultural urbana. Dentro de su práctica pedagógica, Ludoteca mantiene un espacio abierto a la formación sobre interculturalidad a través del juego y la reflexión dirigido a niños, niñas, adolescentes y, docentes hispano ecuatorianos. A la hora de trabajar la interculturalidad en Ecuador, Ludoteca lo hace desde una perspectiva focalizada, es decir, tomando en cuenta el contexto histórico, antropológico y político de 
Ecuador; así como la universalidad de los principios interculturales. El objetivo general es contribuir a la consolidación de la identidad nacional a través de la capacitación en el conocimiento de la interculturalidad de manera conceptual, procedimental y actitudinal con nuestro material didáctico constructivista y reflexivo, tanto a discentes como docentes de la población hispana ecuatoriana.

Ludoteca como proyecto educador que trabaja la Interculturalidad tiene su fundamentación teórica en la Educación Popular de Paulo Freire (1978), la cual originó, a su vez, la teoría de la Pedagogía Crítica desarrollada por Henry Giroux y Peter McLaren, así como su derivado, el modelo pedagógico social.

Desde la perspectiva educativa, la interculturalidad como tema transversal coherente a nuestra antropología nos exhorta a "aterrizar" y, más aún, a socializar sus concepciones en la ciudadanía urbana mestiza ecuatoriana, puesto que

los temas transversales tienen la función de: a) identificar, interpretar y criticar situaciones de injusticia en la realidad y en las normas sociales, b) construir de forma autónoma, racional y dialogante unos principios y una escala de valores que favorezcan la convivencia desde una perspectiva crítica, c) tomar iniciativas y participar activamente en la construcción de formas de vida más justas tanto a nivel personal como colectivo (Ejes transversales 2000).

Tomando en cuenta además que "la metodología de los temas transversales ha de tender a contextualizar los contenidos, tratarlos de forma globalizadora e interdisciplinar, potenciar la interacción, el dialogo, la reflexión y el análisis, la participación y la resolución" es mi propuesta que la interculturalidad ecuatoriana disponga de un curriculum para la Educación Hispana contemplando actividades curriculares y extracurriculares, de ahí que la propuesta se enmarque como estrategia pedagógica urbana y rural.

La Pedagogía urbana reposa sobre la reflexión sistemática de la relación entre lo urbano y lo pedagógico, diseñando el paradigma de la ciudad educativa que articula procesos culturales, sociales y educativos (Nájera 2010). Para Colom (2004) el desarrollo de la ciudad como agencia educadora conlleva la democratización cultural, convirtiéndose por tanto en escuela de ciudadanía, capaz de guiar por los caminos de la paz, la convivencia y la solidaridad. Trilla, observa tres dimensiones de análisis posibles que enriquecen la relación educación y ciudad, estableciendo el paradigma de: 
a) La ciudad como contexto de educación (aprender en la ciudad), espacio donde acontece el fenómeno educativo en toda su extensión asimilable científicamente, educación formal y otras educaciones, además de expresión de una política educacional territorial.

b) La ciudad como medio o vehículo de educación (aprender de la ciudad), como un entorno educativo, un agente de educación, formación y socialización, una escuela de la vida.

c) La ciudad como contenido educativo (aprender la ciudad), como contenido de la cultura a transmitir en el espacio escolar un componente importante del currículo.

Las actividades de Ludoteca encajan en las tres categorías del paradigma de ciudad educativa como lo veremos más adelante.

La constitución de la Pedagogía urbana como praxis deviene a partir de la constatación de las complejidades de la vida actual y el desarrollo de los problemas socio-urbanos, nos dice Colom (2004); por otro lado,

es significativa la importancia creciente que adquieren los factores culturales en la orientación de los procesos urbanos actuales. Por una parte, la conciencia de las desigualdades sociales, el afán de distinción, el miedo a los otros y el refugio en vida privada son muy funcionales al modelo de urbanismo globalizado... Por otra surge una contestación cultural a los impactos de la globalización y de la economía de mercado sobre el territorio (Borja 2007).

Entonces -según Gennari (en Gamboa 2010)-, es urgente repensar pedagógicamente la metrópoli moderna para mantenerse fiel al principio de solidaridad. Hay que repensar al ciudadano como un sujeto cuya formación es inseparable de las transformaciones de la ciudad. En este punto, mi segundo planteamiento para la interculturalidad desde la pedagogía urbana lo formulo de la siguiente manera: ¿es posible acercar la ciudad al campo; fomentar la responsabilidad de los ciudadanos urbanos para con los conciudadanos rurales; las ciudades de cada provincia del Ecuador tejiéndose responsable, histórica y axiológicamente con sus campos?

Avanzando en mi explicación sobre la interculturalidad como estrategia de una pedagogía urbana, quisiera recoger la síntesis que hace Gamboa sobre las 
corrientes y tendencias aglutinantes de las vertientes praxeológicas de la pedagogía urbana en las cuales Ludoteca se enmarca, así:

Educación urbana: corriente centrada en la gestión de los servicios escolares locales, la administración municipal y los problemas sociales en la escuela.

Educación ciudadana: modalidades de acción socioeducativa local que tradicionalmente abarca la participación comunitaria y la mediación vecinal; además, se desarrollan acciones en torno a la educación al consumidor y la educación vial.

Ciudad educativa: proyectos socioeducativos y de participación ciudadana realizados a partir de municipalidades de diversos países, sensibilizadas en la reconstrucción de relaciones entre educación, cultura y participación ciudadana.

Educación ambiental: corriente socioeducativa que se instala en la acción socio-territorial bajo modalidades de educación no formal y grupos de acción ecológica, ambos, abordando el resguardo de los ecosistemas locales y la calidad de vida cotidiana. Esta corriente se ha visto incidente en los ámbitos institucionales escolares toda vez que permea los currículos científicos y la socialización primaria.

Animación sociocultural: prácticas socioeducativas extendidas en varios países latinoamericanos que impulsan la animación comunitaria y la gestión de las culturas locales, encuentro de educación, arte y creatividad. La animación sociocultural conecta los problemas urbanos al protagonismo de los sujetos, habitantes y/o actores locales. Desde la perspectiva institucional se despliega un fragmento especializado: la gestión cultural.

Educación social: pensada inicialmente en torno a los problemas sociales y su asistencia, esta corriente socioeducativa tiene variadas modalidades de intervención educativa no formal para personas en situaciones diversas de exclusión y marginación.

Debido a su gran desarrollo, en algunos países europeos ya se cuenta con una definición profesional y un sustento teórico claro: 
Derecho de la ciudadanía que se concreta en el reconocimiento de una profesión de carácter pedagógico, generadora de contextos educativos y acciones mediadoras y formativas, que son ámbito de competencia profesional del educador social, posibilitando la incorporación del sujeto de la educación a la diversidad de las redes sociales, entendida como el desarrollo de la sociabilidad y la circulación social; la promoción cultural y social, entendida como apertura a nuevas posibilidades de la adquisición de bienes culturales, que amplíen las perspectivas educativas, laborales, de ocio y participación social (ASEDES 2007, 12).

Latinoamérica que se orientan a la promoción humana, la educación para el desarrollo, la educación de adultos y la participación ciudadana. En las últimas décadas ha transitado por opciones alternativas y/o complementarias a la vía escolar. En general se plantean desde una óptica comprometida con los sujetos populares y sus demandas históricas.

Educación patrimonial: tendencia socioeducativa inscrita en la noción del valor de la creación cultural en la historia humana, el sentido de las obras humanas, el espacio natural que nos acoge, el testimonio de los 'tesoros vivos', ejemplos de nuestra tenacidad por ser humanos. Verificamos prácticas en torno al resguardo cultural a través de la educación de museos, la gestión de la cultura de la comunidad, el turismo cultural y el involucramiento de la ciudad en el currículo escolar. Desde algunas tendencias, la preocupación pedagógica por el patrimonio urbano es un factor clave en la proyección de condiciones y oportunidades para la conformación de ciudades sustentables. Todas estas manifestaciones de educación en la ciudad, sumadas las propias de la educación escolar, forman parte del empoderamiento de las dinámicas y procesos ciudadanos. Entonces, la educación en la ciudad puede aportar y/o facilitar la generación de políticas socioeducativas y culturales interconectadas y transversalizadas por los intereses de la gente; potenciamiento del saber social; ampliación de la democratización local; la construcción de una ciudad para todos abriendo la educación a la vida, desde la vida y por la vida. 


\section{Currículum y didáctica social para la interculturalidad en la ciudad}

Ludoteca intenta socializar la interculturalidad en la vida de los ciudadanos ecuatorianos a través de los contenidos y las estrategias didácticas que han surgido de la sistematización de la investigación del tema intercultural en los docentes de la Educación Hispana ecuatoriana. La conclusión de estas sistematizaciones es básicamente la carencia o escaso conocimiento sobre contenidos conceptuales y metodologías de trabajo para la interculturalidad. Ludoteca se planteó entonces las preguntas:

- ¿Cómo se enseña la interculturalidad?

- ¿Cuáles son los contenidos de la interculturalidad?

Para responder a estas interrogantes, como investigadora de este proyecto me apoyé en los 'Criterios de Enseñabilidad para una materia' recomendados por Rafael Flórez en su libro Hacia una Pedagogía del Conocimiento (2000) "las condiciones de enseñabilidad de una ciencia se determinan según sus contenidos, sintaxis, organización y secuencia... y que estas condiciones de enseñabilidad no se deben confundir con su didáctica" (92). Paso a tratar el tema de los contenidos del currículum para la interculturalidad mencionando brevemente que estos se plasmaron en una de las estrategias didácticas que Ludoteca fabricó como soporte para trabajar la interculturalidad, esta fue la elaboración de un texto didáctico, titulado: "Cuaderno de Trabajo para Docentes".

Los contenidos y la didáctica se obtuvieron a través del seguimiento de dos caminos paralelos: el de la selección de los contenidos y el de la selección de elementos para la didáctica de aquellos contenidos. La selección de contenidos para la interculturalidad entonces se basó en:

1) Las problemáticas docentes arrojadas en el diagnostico (detectadas en los talleres).

2) Los contenidos y referentes sugeridos en la Reforma Curricular. 
Para desarrollar los contenidos que operarían en el "Cuaderno de Trabajo para Docentes: Interculturalidad, eje transversal" tomé en cuenta los criterios que hoy la teoría considera necesarios para la selección de contenidos, estos son: validez, significación y adecuación y, a los que Rodríguez Diéguez añade, la interdisciplinaridad "con el fin de que sirva de filtro para facilitar la convergencia o encuentro de contenidos". Para Wheeler, la validez se mide por el grado en el que los contenidos sirven para alcanzar los fines propuestos; significación, por su lado, es entendida como la inclusión en el currículo de aquellos contenidos concernientes a la realidad exterior e interior que se consideran necesarios y característicos de la cientificidad, y la adecuación se refiere a la mentalidad y a los intereses del sujeto educando.

\section{Modelo pedagogico intercultural}

Para Flórez (Hacia una Pedagogía del Conocimiento) primeramente,

el pedagogo opta por un enfoque pedagógico particular que inspire sus metas de formación y aprendizaje seleccione, subordine y jerarquice los temas prioritarios de la materia, así como la secuencia y el abordaje de los conceptos. El enfoque pedagógico autorizará o desautorizará algunas técnicas y métodos de enseñanza, según la coherencia con el enfoque pedagógico elegido y su pertinencia y adecuación al tema de enseñanza.

Según Flórez, un modelo pedagógico originará un currículo diferente. Y aunque el modelo pedagógico solo se basa en los principios fundamentales desde los cuáles se forma al alumno, cada ciencia tiene su propia didáctica y esta influye necesariamente al currículo.

Veamos entonces los lineamientos principales de nuestro modelo pedagógico para la interculturalidad y la didáctica que hemos de utilizar para enseñarla.

\section{Principios para el modelo pedagógico intercultural}

Los principios pedagógicos de la interculturalidad se han esbozado con miras hacia la edificación y consolidación de la identidad nacional del ciudadano a través del desarrollo de una competencia intercultural. Así se conceptúa la interculturalidad de modo general como principio 
- activo de los códigos de convivencia de una sociedad culturalmente diversa (Educación para la Paz)

- de desarrollo de las competencias: conceptual, técnica, de integración y de adaptación,

- de desarrollo cultural sostenible de la comunidad.

- de fortalecimiento de identidad nacional en el ciudadano

- de desarrollo de la identidad mediadora del ciudadano.

De manera específica, los principios pedagógicos para el Modelo Pedagógico Intercultural, son:

Creatividad que recogemos de Medina Revilla, 2009. Interdisciplinaridad e integración de áreas.

Hermenéutica: la predisposición a la indagación, a la pregunta erguida permanentemente.

Axiología: los valores que respaldan o que motivan el actuar humano.

Teleología: los fines del actuar humano.

\section{Principios Constructivistas}

- Parte de ideas previas y preconceptos.

- Prevé el cambio conceptual.

- Confronta las ideas previas y preconceptos con el nuevo concepto.

- Aplica el nuevo concepto a situaciones concretas y lo relaciona con otras para su aplicabilidad y funciones (constructivistas)

\section{Principios Pedagógico-Sociales}

- Los retos y los problemas a estudiar son "tomados de la realidad", no son ficticios ni académicos y la búsqueda de la solución ofrece la motivación intrínseca que requieren los estudiantes.

- El tratamiento y búsqueda de la situación problemática se trabaja de manera integral, no se aísla para llevarla al laboratorio sino que se trabaja con la comunidad involucrada en su contexto natural mediante una práctica contextualizada. 
- Aprovechamiento de observar a los compañeros en acción, no para imitarlos, sino para revelar los procesos ideológicos implícitos.

- La evaluación en la perspectiva es dinámica, porque lo que se evalúa es el potencial de aprendizaje que se vuelve real gracias a la interacción del alumno con aquellos que son mas expertos que él. Realizar esfuerzos colectivos no solo de indagación científica.

\section{Principios de investigación-acción participativa:}

- Recuperar y reinterpretar la historia olvidada o tergiversada de las luchas populares.

- Valorar las propias raíces como pueblo y utilizar para estas tareas elementos de la cultura y del saber cotidiano, del arte y de la ciencia popular.

- Comunicar los resultados del trabajo tomando en cuenta niveles de comprensión de las comunidades en formas diversas o estilos diferentes (Fals Borda 1992).

\section{Principios de la andrología o Pedagogía del adulto}

\section{Horizontalidad}

La horizontalidad es donde el facilitador y el estudiante tienen características cualitativas similares (adultez y experiencia), pero la diferencia la ponen las características cuantitativas (diferente desarrollo de la conducta observable).

\section{Flexibilidad}

Es de entender que los adultos, al poseer una carga educativa-formativa, llena de experiencias previas y cargas familiares o económicas, deben necesitar lapsos de aprendizaje acordes con sus aptitudes y destrezas.

Ahora, veamos qué entendemos por currículo. Definimos currículo como "el mediador", o canalizador pedagógico entre la teoría y la práctica de la enseñanza con los alumnos. Mientras que la enseñanza es la actividad misma de enseñar, la cual puede ser de varias formas. El currículo es la manera práctica de aplicar una teoría pedagógica a la enseñanza en el aula. Cada teoría pedagógica o modelo genera una propuesta curricular diferente. Stenhouse lo define como "objeto de acción simbólico y significativo para maestros y alumnos encarnado 
en juegos, palabras, imágenes, sonidos, etc.” El diseñador del currículo, además de pedagogía necesita conocer a sus alumnos, sus intereses y necesidades y los de la comunidad sociocultural de la que ellos hacen parte, de modo que el currículo resulte pertinente (Flórez, Hacia una Pedagogía del Conocimiento, 293). El nuevo currículum que propongo contempla las siguientes partes: 1) ontología de la interculturalidad, 2) teleología de la interculturalidad, 3) axiología de la interculturalidad, 4) deontología de la interculturalidad, 5) las tres íes: interculturalidad, interdisciplinaridad e integración de áreas, 6) el método de la interculturalidad, 7) mediación e interculturalidad, 8) transversalidad y 9) interculturalidad como modelo pedagógico.

\section{Modelo didáctico intercultural}

En lo que respecta a la didáctica, recojo lo afirmado por Flórez "el pedagogo no podrá formular una didáctica pertinente y específica mientras no domine la ciencia que pretende enseñar" (Hacia una Pedagogía del Conocimiento, 2000). Habiendo ya cursado Pedagogía Intercultural A y B, reuní mi propia experiencia académica y cognitiva sobre la interculturalidad para ayudarme con una didáctica apropiada para enseñar la interculturalidad a maestros de la Educación Hispana.

La didáctica fue determinada por los modelos constructivista, social, investigación-acción participativa, la enseñanza por procesos así como por su posición como eje transversal en el currículo ecuatoriano, los principios de la andragogía y la educación recurrente que veremos a profundidad más adelante. La didáctica empleada en esta obra está fundamentada en principios pedagógicos constructivistas y corresponde además a las cuatro competencias esenciales del aprendizaje: el conocer, el hacer, el ser y el convivir.

En nuestro caso con la didáctica de la interculturalidad se desarrolla tomando en cuenta:

1) la naturaleza de la interculturalidad que es eminentemente reflexiva y actitudinal, lo cual nos lleva a trabajar con el modelo pedagógico constructivista y por procesos.

2) los contextos políticos, sociales y culturales en los que se está educando sobre ella como eje transversal para diseñar los ejercicios de aplicación de los contenidos, lo cual nos lleva a trabajar con el modelo pedagógico 
freiriano. Veamos detalles sobre los modelos pedagógicos mencionados pertinentes a la enseñanza de la interculturalidad.

Partiendo del enfoque o el modelo pedagógico, el currículo, que son los contenidos siguiendo la misma línea social o crítica, me queda el modelo didáctico intercultural esbozado:

- El juego

- Las historias de vida

- Los proyectos de vida -integrados individuales y grupales (aprendizaje para toda la vida, aprendizaje significativo)

- Elaboración creativa de material didáctico propio o colectivo.

\section{Estrategias didácticas sociales del proyecto de ludoteca}

Los beneficiarios inicialmente del proyecto de Ludoteca fueron los docentes de la Educación Hispana. Hoy se ha extendido el proyecto hacia la población infantil.

El proyecto consiste en un programa de formación sobre interculturalidad compuesto de tres partes, de las cuales, las dos primeras serán desarrolladas en esta ponencia desde su marco teórico:

a) Ludoteca Intercultural. Consiste en la confección de material didáctico intercultural para niños y niñas en edad escolar y adolescente. Existe la gran necesidad de desarrollar herramientas didácticas que formen específicamente en el conocimiento de la interculturalidad a nivel pedagógico-cultural.

b) Talleres de formación actitudinal sobre interculturalidad como eje transversal para docentes de la Educación Hispana, a partir del texto Cuaderno de Trabajo para Docentes.

c) Talleres de elaboración de material didáctico intercultural para docentes de la Educación Hispana.

Fröbel contribuyó a la teoría del aprendizaje introduciendo el juego como parte del aprendizaje del niño e incluyendo el juego en el currículum. 
El juego es la actividad más pura y espiritual del hombre en esta etapa y al mismo tiempo típico de la vida total del ser humano -de la vida interior y de todas las cosas... Los juegos del niño son las hojas germinales de toda la vida posterior para que el hombre se desarrolle y se muestre en éstas, en sus disposiciones más tiernas, en sus tendencias más tiernas.

Concibió las "ocupaciones" como materiales diseñados para hacer que los niños de enrolen en actividades de aprendizaje.

\section{¿Cómo se aprende?}

Ludoteca Intercultural ha tomado las siguientes vertientes teóricas sobre el aprendizaje para estructurar su trabajo pedagógico: Piaget sostenía que el aprendizaje implica:

1) Descubrimiento

2) Manipulación de los objetos fomenta el aprendizaje

3) Las interacciones con personas y cosas llevan al desarrollo del intelecto yal conocimiento

Howard Gadner decía que la inteligencia es multidimensional y que el potencial humano es la habilidad para resolver problemas. Existen muchas formas de conocimiento y de expresar ese conocimiento. Comenio tenía algunas ideas sobre el juego. Creía que, dirigido por alguien bondadoso e inteligente, era una bendición: para el pensamiento, por la observación de novedades y las imágenes; para la razón, por haber varias clases de obstáculos; para la memoria, por la repetición; para el juicio, por los acertijos y las disputas; para la retórica, por los discursos, las cartas y los diálogos improvisados.

\section{Curriculum para la educacion hispana en Ecuador}

Para efectos de la elaboración del Cuaderno de Trabajo para Docentes: Interculturalidad, eje transversal he recurrido a la pedagogía normativa, filosófica, tecnológica, descriptiva y de ciencias humanas auxiliares como la Antropología, Sociología y Política para responder preguntas pedagógicas sobre la interculturalidad necesarias. 


\section{Primer contenido curricular: ontología pedagógica de la inter- culturalidad}

La ontología pedagógica se encargó de dilucidar: a) el concepto de educación b) el concepto de interculturalidad c) el concepto de pedagogía intercultural d) el sujeto de la educación: la condición de discípulo: el docente de la Educación Hispana.

\section{a) Concepto de educación}

Para Flórez (Hacia una Pedagogía del Conocimiento, 107 -108, 2000) la actividad principal de la educación es la de formación y alude a Humboldt:

Pero cuando decimos formación nos referimos a algo más elevado y más interior, al modo de percibir que procede del conocimiento y del sentimiento de toda la vida espiritual y ética y se derrama armoniosamente sobre la sensibilidad y el carácter. La formación en este sentido no es sólo el resultado espiritual sino también el proceso interior en permanente desarrollo que abarca mucho más que el simple cultivo de las aptitudes y talentos naturales del individuo. En la formación uno se apropia por entero y perdurablemente de aquello en lo cual y por lo cual uno se forma... Lo esencial de la formación humana es convertirse en un ser espiritual capaz de asumir sus propios deseos, necesidades e intereses privados y ascender a la generalidad, universalidad espiritual, a través del trabajo y de la reflexión teórica hasta reconciliarse consigo mismo.

\section{b.1) Interculturalidad}

Consideramos el primer valor de la interculturalidad el formar sujetos competentes interculturalmente; sujetos de dialogo, sujetos de paz. Toda cultura es básicamente pluricultural. Es decir, se ha ido formando, y se sigue formando, a partir de los contactos entre distintas comunidades que aportan sus modos de pensar, sentir y actuar. Evidentemente los intercambios culturales no tendrán todos las mismas características y efectos. Pero es a partir de estos contactos que se produce el mestizaje cultural, la hibridación cultural. Mientras que el concepto "pluricultural" sirve para caracterizar una situación, la interculturalidad describe una relación de aprendizaje entre culturas. 


\section{b.2) Interdisciplinaridad}

La interculturalidad es un concepto inherente a las Relaciones Interculturales, concebida esta como materia interdisciplinaria. William Hart en su artículo Intercultural Relations: The history of an interdiscipline cita la definición de Littlejohn $(1982 ; 246)$ de lo que es una materia interdisciplinaria, así pues, es la comunidad de académicos que se identifican con varias disciplinas pero que comparten el interés común sobre un tópico en particular que académicamente "cruza" las fronteras opuestas tradicionales entre materias. Littlejohn hace notar la ardua tarea conceptual que un estudio interdisciplinario acarrea:

el peligro reside en lo vasto en que el campo académico puede convertirse, de manera que se hace difícil manejar toda la información de manera apropiada. En el campo del conocimiento, la interdisciplinaridad ofrece un camino para superar aquella fragmentación del saber que la especialización parece hacer inevitable, permitiéndonos realizar una cierta unidad del saber, no como una "reducción a la identidad (Littlejohn 1982).

sino como toma de conciencia de la complejidad de las realidades que nos rodean, la cual requiere que el verdadero entender de esta complejidad consista en tomar en cuenta las diferencias y al mismo tiempo comprender las razones y el sentido de estar juntas y relacionadas. De la misma forma que se busca la unidad en la diversidad de culturas, se busca la unidad del saber en la diversidad de estos.

\section{b.3) Integración de áreas}

Muchas veces la labor educativa, la inercia, la burocratización, nos hace actuar como si creyéramos que primero surgieron los conceptos y luego los procedimientos; que primero las áreas y luego los contenidos y por último los seres humanos; y nos lleva también a olvidar que la razón de ser de la escuela es la sistematización de aquellos saberes socialmente significativos que ayudarán a los sujetos esencialmente a aprender más de sí mismos, de los otros y del mundo en el que viven; por la integración de áreas es eminentemente necesaria para el desarrollo de las competencias procedimentales y actitudinales completando la competencia conceptual o cognitiva del discente. 


\section{c) Concepto de pedagogía intercultural}

La pedagogía intercultural como disciplina se interesa por educar en tolerancia frente a las diferencias culturales. Puede ser llamada pedagogía de la diferencia pues se dedica a disolver rupturas, fusionar criterios y perspectivas y aproximar hendijas culturales. La interculturalidad como proceso socio psicológico es inherente, resultante y objeto de estudio de la pedagogía intercultural tomando en cuenta todos sus fines filosóficos, psicológicos, antropológicos, sociológicos, políticos y pedagógicos. En relación a la corriente del multiculturalismo aplicado en sociedades altamente pobladas por minorías culturales, la diferencia entre ambas es clara. El interculturalismo no se empeña solamente en la interrelación y en la aproximación al Otro, sino en el aprendizaje mutuo. Enseña en el valor de la diferencia a través de la tolerancia y el respeto. Las minorías han luchado vasta y profundamente por el derecho al reconocimiento de su identidad cultural. Es decir, las políticas culturales de un Estado deben siempre incluir lo que Kymlica llama una política de reconocimiento. El Estado ecuatoriano ha omitido en su programa de progreso en desmedro de la madurez del consciente colectivo histórico ecuatoriano, el conocimiento generador de una visión más auténtica del nacionalismo ecuatoriano. Pues es posible probar en distintos aspectos la visión parcializada e incompleta de la realidad de identidad que tienen sus ciudadanos. La educación y la historia son fuentes inseparables del desarrollo de sujetos históricamente responsables y políticamente conscientes, activos, capaces de conducir el curso de la sociedad a la que pertenecen. La falta de conocimiento de conceptos interculturales al interior de la ciudadanía ecuatoriana ha menguado el efecto de la lucha de los diferentes movimientos sociales étnicos del país, empezando por el que más protagonismo ha tenido: el indígena. Además de confrontarse inevitablemente con su propia inexperiencia política, confrontan la inmadurez cultural y política de sus conciudadanos no tan étnicos.

\section{d) Sujeto de la educación: condición del discípulo}

El docente fiscal de la Educación Hispana se encuentra con falta de estímulo y capacitación para intervenir adecuadamente en el área. Perteneciente en su mayoría a estratos socioeconómicos medio-bajo y bajo, es inconsciente, en la mayoría de los casos, de sus propios prejuicios y sus consecuencias. 


\section{Segundo contenido curricular: teleología de la interculturalidad}

El término interculturalidad es todavía un concepto relativamente inexplorado y es necesario nuevas aportaciones y ampliaciones conceptuales, pues coincidiendo con Moya en que "la interculturalidad no puede quedarse en el mero reconocimiento de las diferencias, sino que debe convertirse en propuesta política con sustento ideológico" (Moya 2004; 168).

Ya que la "categoría conceptual de la interculturalidad está cargada de intencionalidad política y sus prácticas deben ser tener una orientación teleológica" (Moya 2004; 74). En relación a la teleología, es decir, a los fines, he concluido, desde la sistematización de los talleres de diagnóstico y su respectivo análisis en los siguientes campos: psicológico, sociológico, antropológico, político y pedagógico.

\section{Primer fin, el psicológico: la identidad del ser y sus conflictos}

El centro de atención de los procesos de interculturalidad es la identidad del ser. El autor Antikainen sostiene que una identidad rígida y restrictiva podrá ser destructiva puesto que la identidad debe proporcionar flexibilidad y apertura de actitud hacia situaciones nuevas en las cuales las condiciones externas desafían a la persona hacia el cambio de acciones, hábitos y pensamiento.

Ahora bien, como lo ha mencionado una lingüista, interculturalista, Janet Bennet

para formar la competencia intercultural de nuestra identidad es necesario trabajar elementos axiológicos, cognitivos y psicológico-afectivos en la persona. Los axiológicos se refieren a los valores o principios necesariamente presentes en una personalidad para desarrollar su competencia intercultural. Los cognitivos se refieren al conocimiento o saberes sobre su cultura y la que confronta y los elementos psicológicos-afectivos son todos aquellos que estructuran a priori al ser de la persona y que deberán ratificarse o modificarse según constituyan un obstáculo en el desarrollo de la competencia intercultural a la que aspira la persona.

En el plano psicológico las identidades que entran en esta práctica cultural atraviesan un proceso que R. S. Zaharna lo define como colisión del ser. Este concepto está íntimamente ligado al concepto del ser, el otro y el com- 
portamiento (Zaharna, International Journal of Intercultural Relations, 13, 501-526). El contacto con el otro diferente produce ansiedad en la identidad y efectos dolorosos causados por la confusión de la identidad en su proceso de ajuste hasta llegar al entendimiento y consolidación de aquellos nuevos elementos que forman parte de su identidad cultural. Es aquí donde el concepto de la colisión del ser es introducido. La colisión del ser es una intromisión inconsistente y conflictiva de auto imágenes. Tres dimensiones de la autocolisión son presentadas: la pérdida de la competencia comunicativa, las reflexiones en el ser como respuesta del contacto con el Otro y las modificaciones o cambios en la identidad reflejado en el comportamiento. Zaharna sostiene que el desafío que sufre la identidad en este tipo de situaciones es un proceso más que un resultado. Janet Bennett $(1997,48)$ subraya que el sentido de identidad de la persona en el proceso intercultural está en riesgo para aquellos quienes cruzan las fronteras o límites de su propia identidad en confrontación con la amenaza de la nueva cultura.

\section{Segundo fin, el antropológico: el yo y el Otro.}

Para ilustrar el contenido del fin antropológico que nos ocupa en este apartado me apoyaré en el libro Borderlands/La frontera: The new Mestiza de Gloria Anzaldua, en el cual trabaja eficientemente el concepto de "frontera", muy apropiado cuando tratamos de "diálogos", de encuentros. El libro comprende una serie de ensayos y poemas que exploran la identidad, cada una dibujando sobre la experiencia personal de Anzaldúa como Chicana, lesbiana y activista. Anzaldúa desafía la concepción de frontera como una simple división, reconceptuándola como un área para ser habitada y que comprende parte de una identidad. Gloria Anzaldua opina que el concepto de frontera (border) puede adquirir diferentes definiciones, físicas o metafóricas y es un concepto que se internaliza. Ella explora la idea de la "Consciencia de la frontera".

La mestiza enfrenta el dilema de la raza mezclada: a qué colectividad escucha la hija de una madre de piel obscura?... Acuñada en una cultura, atrapada entre dos culturas, llevando todas tres culturas y sus respectivos sistemas de valores La Mestiza atraviesa una lucha de fronteras, una guerra interna. Desde cruces raciales, ideológicos culturales y biológicos, una consciencia alienígena está presente en la formación de una nueva consciencia mestiza, es la consciencia 
de la frontera - Anzaldua, Gloria. Borderlands/La frontera: The New Mestiza. Norton anthology oftheory and Criticismo.

En una entrevista ella dice:

Empecé a pensar, "Si, soy una chicana, pero eso no es todo lo que soy, $\mathrm{Si}$, soy una mujer, pero eso no es todo lo que soy. Sí, vengo de la clase trabajadora, pero ya no soy más de la clase trabajadora. Sí, vengo del mestizaje, pero que parte de ese mestizaje tiene privilegios? Sólo la española, y no la indígena o negra" Empecé a pensar en términos de una consciencia mestiza. ¿Qué pasa con toda esa gente que como yo están entre todas estas categorías? ¿Qué hace eso con el concepto de nacionalismo que uno tenga, de raza, o incluso de género? Intentaba articular y crear una teoría de la existencia de la Frontera ... Tenía que hacerlo, por mí, descubrir otro término que pudiera describir un nacionalismo más poroso, abierto a otras categorías de identidad. - Gloria E. Anzaldúa, Entrevistas.

Hay fronteras entre las personas. Kevin Robins en el libro New Keywords nos dice: "Las identidades no pueden ser autosuficientes. Ellas son realmente instituidas a través del juego de las diferencias, constituidas en y a través de sus múltiples relaciones con otras identidades. Identidad podría ser definida por lo que se excluye en ella, por ejemplo lo que pone fuera de sus límite" (Benett, Grossberg y Morris; Ed.)

Aztlan, o la patria es lo que Anzaldúa describe como "dos mundos fusionándose para formar un tercer país - una cultura fronteriza". El territorio, previamente poseído los españoles y luego por los mexicanos, es lo que hoy comprende las regiones de Texas Colorado, California, Nuevo México, Arizona, Utah and Nevada. Es un lugar difícil de definir porque sus habitantes no sienten realmente que pertenecen a México o a los Estados Unidos. Ellos son los de los "ojos entrecerrados", los perversos, los raros, los problemáticos, los mulatos, los media raza, los medio muertos ... Aunque está claro que Anzaldúa está preocupada por la calidad de vida del Chicano en Aztlan, muchas personas en los Estados Unidos se preocupan por el Aztlan por una razón diferente: Ellos creen que el Aztlan pone a Estados Unidos en una peligrosa masiva inmigración ilegal, y posiblemente incluyendo la sucesión de una parte del país. El Aztlan desde el punto de vista de la interculturalidad es ese espacio de la nueva concepción, del lugar donde se dan los consensos, el espacio donde se da la reconstrucción. 


\section{Tercer fin, el sociológico: política del reconocimiento de la diferencia}

El tercer fin, el sociológico, nos trae a Charles Taylor, cuya teoría del reconocimiento de la diferencia, centra el estudio en la identidad moderna del individuo. Para Taylor la identidad del yo está en parte definida por la identidad de la comunidad. Por ello, establece una especie de binomio entre el individuo y la comunidad, resaltando su mutua interacción. De esta forma, Taylor señala que la identidad de la comunidad debe ser reconocida, tal y como lo es la del individuo, y aboga por una política de reconocimiento de las diferentes identidades:

...la política del reconocimiento aboga por políticas permanentes a favor de las distinciones nacidas de la defensa de la propia identidad, mientras la política de la dignidad defiende la garantía de oportunidades; "la política de la dignidad igualitaria se basa en la idea de que todos los seres humanos son igualmente dignos de respeto" en atención a nuestro potencial humano universal racional. "También podríamos decir que se fundamenta en un potencial universal, a saber: el potencial de moldear y definir nuestra propia identidad, como individuos y como cultura.

Señalábamos que, para Taylor, la identidad de la comunidad es parte constitutiva de la identidad del individuo. Pero, ¿en qué consiste la comunidad? ¿qué es la comunidad? Taylor contempla la comunidad como comunidad de sentido. La comunidad ofrece los marcos valorativos adecuados donde se desarrolla el lenguaje que posibilita dotar de sentido las distintas valoraciones morales. De esta forma, será la comunidad como comunidad de sentido la que ofrezca, a través del lenguaje, las significaciones densas que permitan al individuo hacerse inteligible frente a sí mismo (orientarse en el espacio moral) y frente al resto de los individuos de la comunidad.

Los seres humanos, en tanto que se autointerpretan, requieren de las densas significaciones que les ofrecen los lenguajes, y estos lenguajes son fenómenos sociales que se estructuran y mantienen en contextos comunitarios. Por tanto, la comunidad de sentido es la comunidad lingüística propia de cada individuo. Esta comunidad de sentido o comunidad lingüística posee una identidad propia, definida y colectiva. Por ello, habla de la identidad colectiva de un grupo o comunidad, y no solo de la identidad individual. En este sentido, señala que la identidad colectiva de la comunidad se define, principalmente, en términos lingüísticos, pues es el lenguaje el que ofrece los significados densos y los mar- 
cos valorativos que permiten que los individuos se vuelvan inteligibles frente a ellos mismos y frente al resto de la comunidad.

Esta argumentación conduce a uno de los aspectos más destacados del pensamiento de Taylor: la identidad de la comunidad y el problema de su reconocimiento. En este sentido, cabe señalar que reconoce (hace suyo) el discurso democrático de los derechos (autonomía personal, libertad, igualdad, gobierno democrático). Sin embargo, introduce dos importantes modulaciones al mismo: primera, incorporar como resultado del debate público una política sustantiva y concreta orientada al bien común; segunda, desplazar la idea de los "derechos individuales" a favor de los "derechos colectivos y culturales" en dos supuestos concretos. El primero, en el caso de las políticas de reconocimiento institucional como una forma de bien común propio a una comunidad interna específica ("derechos colectivos" como "políticas de reconocimiento") -se trata del supuesto del multiculturalismo en un Estado político-o El segundo supuesto lo constituye el derecho de autodeterminación de las naciones morales tradicionales ("derecho colectivo" a la independencia política). En ambos casos, la tesis latente es la esencial e íntima vinculación entre el "reconocimiento" y la "identidad", ya que nuestra identidad colectiva se encuentra parcialmente definida por el reconocimiento o por la falta de este.

Esta posición de Taylor es uno de los fundamentos de la interculturalidad pues da al imprescindible diálogo que debe tomar lugar en momentos de conflictos o encuentros de diferencias que requieran de consensos y soluciones. Para el diálogo y la aceptación de la diversidad es necesario aplicar la comprensión pedagógica que Flórez describe como

otra manera diferente de comprender al tú reconociendo como persona, como álter ego, todavía bajo la referencia exclusiva de uno mismo. Corresponde a la mayoría de las relaciones vitales entre los hombres, en las que se da una reciprocidad dialéctica y un mutuo reconocimiento de la posibilidad de anticiparse y aprehender al otro desde sí mismo en plano de igualdad (Hacia una Pedagogía del Conocimiento, Flórez, 226). 


\section{Cuarto fin, el político: La interculturalidad como principio mediador político entre identidades y sus derechos}

Democracia es, entre otras cosas, la posibilidad de un espacio para una transformación social que nace de la participación popular. Entiéndase por participación popular un derecho político que al ser ejercitado permite a los seres del pueblo convertirse en ciudadanos, en productores políticos para dejar de ser simplemente consumidores políticos. La participación popular se puede concretar en muchas formas, una de ellas, basándose en su calidad de sociedad civil que Gramsci concibe como el terreno de la actividad y lucha política (Dagnino 1998; 38), es la conformación y organización de movimientos sociales. La participación del individuo en movimientos sociales, sean estos directos protagonistas o no del escenario político, lo convierte en sujeto político activo que escribe historia y que crea espacios que posibiliten la transformación social. En la construcción de movimientos sociales radica implícita la idea de los individuos que se constituyen como ciudadanos de una comunidad política organizándose en movimientos sociales para convertir sus reclamos en derechos (Joyce Sánchez E., Ensayos sobre interculturalidad). Esta interpretación de la actividad de los movimientos sociales se deriva de la noción de ser/convertirse-a travésdel-actuar (Foweraker y Landman 1997). Entiéndase por Cultura política "una construcción social, particularísima de cada sociedad acerca de lo que es considerado como político" (Dagnino, 1998), incluyendo la forma y parámetros en que la "socialización política" toma lugar; así, la socialización política es el proceso por el cual las ideas-principios de los individuos se convierten en normas de comportamiento político; es el entendimiento colectivo del adecuado comportamiento político que genera cambios en las identidades, intereses y comportamientos (Keck, Sikkink y Ropp 1999). La interculturalidad como cultura política y política cultural está en procesos de socialización política y ciudadana, lo cual explica por qué hasta ahora muchos de los diálogos sostenidos entre indígenas y mestizos no genera mucho fruto y sigue marginalizado este encuentro. Considero que estamos despertando como nación a nuestra diversidad cultural y pasando, por lo tanto, por una fase de reconocernos y actuar más allá del marco de la pluriculturalidad. La dimensión política de la cultura se puede apreciar cuando los cambios culturales constituyen el objetivo de las luchas y el accionar político; y la dimensión cultural de la política se aprecia cuando las prácticas culturales constituyen el instrumento para alcanzar trans- 
formaciones políticas (Dagnino 1998; 45). Jordan y Weedon en Dagnino nos explican:

La política cultural determina los significados de las prácticas sociales y más aún, determinan qué grupos e individuos gozan del poder de definir estos significados. Puesto que la cultura contribuye a definir el sentido y percepción que tenemos de nosotros mismos, a la política cultural le interesa las subjetividades e identidades. Nuestras subjetividades juegan un papel determinante en los actos de aceptación o rechazo y lucha contra las relaciones de poder existentes...

Así, cuando los movimientos populares atienden y crean nuevos conceptos alternativos remueven las bases sobre las cuales los significados y significantes de la cultura dominante están cimentadas... a través de su participación en debates políticos desafían las prácticas políticas imperantes (Dagnino 1998, 5-7).

El movimiento indígena ecuatoriano desde su nacimiento ha ido renovando las bases del nacionalismo ecuatoriano, desdibujando poco a poco esquemas socio-culturales colonialistas, es decir, "desafiando prácticas políticas imperantes" desde la época colonial. Pero hoy existe el desafío de liderar los cambios a través de la socialización de la interculturalidad en la población mestiza ecuatoriana que no necesariamente está siendo respaldado por los movimientos étnicos del país.

En la mayoría de los casos el objetivo de los movimientos sociales va más allá de las ganancias materiales o institucionales que podrían obtener a través del accionar político. Al imponerse como objetivo principal y último de su acción política el cuestionamiento de las fronteras de las llamadas representación cultural y política y sus prácticas podemos tranquilamente afirmar que los movimientos sociales están en busca, principalmente, de la transformación de la cultura política dominante en la cual ellos operan y en la cual deben constituirse como actores sociales con pretensiones políticas. Es decir, en muchos casos, los movimientos sociales no están demandando inclusión sino que su objetivo es reconfigurar la cultura política dominante (Dagnino 1998; 8).

La acción de los movimientos sociales no apunta a rehusar a la institucionalidad política o a rehusar del Estado, sino su mayor interés es hacer un reclamo radical para su transformación (Foweraker y Landman 1997, 47, mi traducción y énfasis). Baierle (Dagnino 1998, 8) sugiere que los movimientos sociales a 
veces desempeñan un papel fundamental en la transformación del orden político en el cual operan enfatizando que los nuevos ciudadanos que surgen cuestionan radicalmente el modo en el cual el poder ha de ser ejercido más que un simple intento de conquistar este poder.

Los movimientos sociales al luchar por sus derechos de identidad respaldan el espíritu del pueblo frente a la amenaza de desintegración y el olvido por la presencia de la globalización.

\section{Quinto fin, el pedagógico: interculturalidad como pedagogía descolo- nizante}

La importancia de iniciar procesos de interculturalidad en una sociedad pluricultural radica en que éstos apuntan a disolver esquemas de exclusión cultural. Si las políticas culturales como todo lo demás "oficial" emana del estado, entonces debemos esperar tener un estado intercultural, es decir, uno con actitud y aptitud interculturales. Actualmente el Ecuador es formalmente un estado que se reconoce pluricultural (Art. 2 de la Carta Constitucional) y predica la interculturalidad como principio en la Carta Magna. En lo que respecta a la población mestiza, estamos en procesos de socialización política con todo el bagaje propio de la interculturalidad, y más sentida es esta deficiencia en clase profesional docente hispana mestiza. La cultura como concepto es una estructura desigual, cambiante e irregular. La cultura refleja las subjetividades de los individuos que la conforman -cultura e individuo confluyen constantemente. La diversidad cultural es una masa de saberes que puede ser moldeada de acuerdo a la consciencia que se tenga de sus virtudes para ser utilizada como recurso constructivo o para ser desaprovechada y, por lo tanto, me atrevería a aseverar que al no ser aprovechadas debidamente tienden a ser recurso fragmentario. En el primer caso es un proceso enriquecedor, expresión fiel de democracia y tolerancia. El segundo, es su lado más obscuro, pues genera xenofobia, racismo, y muchas otras formas de exclusión. La interculturalidad es, en este respecto, una expresión positiva de interrelación y aprendizaje significativo. Implica el desafío de aprender desde varias perspectivas. La interculturalidad es un esquema más complejo que el de la multiculturalidad porque presupone condiciones individuales y colectivas en el medio de desarrollo que apoyen, respalden, fomenten espacios de diálogos entre lectores culturales diferentes. Mientras que 
la multiculturalidad se conforma con tolerar su existencia. (País pluricultural, país intercultural Joyce Sánchez E. en Ensayos sobre Interculturalidad)

Pedagógicamente la interculturalidad como hemos visto apunta a la formación del ser, con su consentimiento hacia ser un sujeto de mediación cultural. Este fin no es posible alcanzar sin aplicar el elemento de la comprensión pedagógica. Toda comprensión se realiza desde el propio horizonte histórico, desde los propios prejuicios y expectativos de sentido. La comprensión es un proceso de fusión de horizontes. Lo que importa es experimentar realmente al tú en cuanto alteridad reductible..., se trata de conocerlos sin anticiparlo..., para ello se requiere desear que el otro hable, es decir, estar abierto a la expresión libre del otro.

Comprender al Otro no significa aprehenderlo, abarcarlo. Saber escuchar al Otro tampoco significa obedecerle. En la comprensión psicológica las ideas del Otro interesan solo como expresión de su subjetividad. Toda comprensión pedagógica es una búsqueda de acuerdo alrededor del tema o asunto de que se trate, partiendo del dialogo entre los horizontes previos de maestro y alumno.

\section{Tercer contenido curricular: deontologia de la interculturalidad}

La interculturalidad nace desde una visión del consenso y la mediación: en la comunidad académica internacional es reconocida como el "dialogo de culturas". La palabra diálogo, en este respecto, representa más que una simple plática entre dos interlocutores. Etimológicamente diálogo proviene de las palabras griegas diá que significa a través y logos que significa ciencia; la palabra griega dialogus se usaba como ciencia del discurso y su "arte", la dialéctica, se usaba como método para llegar a la verdad mediante la oposición racional de discursos. La dialéctica para los griegos que hace referencia a la conversación como acto era considerada más que una técnica; era considerada como un arte. El arte de conversar, y como tal, era más que hablar y dejar hablar. Como arte lleva implícita virtudes, las cuales a su vez implican un esfuerzo humano. La interculturalidad persigue comprender y asimilar la perspectiva del otro y además, como si fuera poco para nuestro egocentrismo humano, implica aprender del otro. De tal manera que, como podemos apreciar, la interculturalidad en su forma más profunda requiere de un acto volitivo de cada individuo pues en este "intercambio de pensamientos" todos ganamos, porque perseguimos la verdad y no el bien o el interés individualizado. 
Para llegar a este fin, axiológicamente, la interculturalidad pondrá en práctica dos virtudes: la tolerancia y la prudencia. Ambas interactúan permanentemente ampliando los límites de la democracia y de-limitándola para que todos obtengan un beneficio o rédito así como una obligación o limitación. La tolerancia expande los límites de la democracia al permitir la coexistencia de iuris de la diversidad, y la prudencia, estará pendiente de que esta tolerancia no se extralimite, a tal punto de perjudicar a otros. Recordemos pertinentemente que en aras de la justicia y la equidad los principios jurídicos "mi derecho termina, donde empieza el del otro" está vigente en el caso de la interculturalidad. Es decir, existe una flexibilidad que impregna la convivencia. En un marco democrático la interculturalidad responde a este principio jurídico que corresponde axiológicamente a la prudencia.

Algún diccionario dice que la prudencia es la virtud de actuar de forma justa, adecuada y con cautela. De comunicarse con los demás por medio de un lenguaje claro, literal, cauteloso y adecuado. De crear respetando los sentimientos, la vida y las libertades de aquellos quienes se puedan ver afectados por tu creación, sea esta tecnológica o artística. Dentro del dialogo y la mediación, la prudencia es recomendada. Por lo tanto, la buena combinación de la tolerancia y la prudencia trabajaran sobre el dialogo y la mediación, como herramientas para mantener en buen estado a la sociedad. La tolerancia tiene una de sus principales justificaciones en que resulta imprescindible para el conocimiento. Si queremos saber, hemos de estar dispuestos a aprender de los demás y a cuestionar nuestra opinión. En esto radica el talante tolerante. Este carácter no es sino el de quien sabe escuchar a los demás y dialogar con ellos sin más pretensión que la búsqueda de la verdad. Para ello, resulta necesaria la autenticidad y la lealtad en la discusión. Si se discute con otras pretensiones no estamos buscando verdades ni siguiendo las reglas de una discusión racional.

J. Benthan (1834) define por primera vez la deontología en general, como la "ciencia de los deberes o teoría de las normas morales". Aplicada a las profesiones se denomina deontología profesional y es la disciplina que se ocupa de determinar y regular el conjunto de responsabilidades éticas y morales que surgen en relación con el ejercicio de la profesión, especialmente aquellas de dimensiones que tienen repercusión social. Para efectos de nuestro tema, la deontología del docente intercultural, queda resumida en buenos términos por Francés Carbonell (2000) de la siguiente manera: 
1. Educarás con la convicción de la igualdad humana y contra todo tipo de exclusión.

2. Respetarás a todas las personas, pero no necesariamente todas sus costumbres o sus actuaciones.

3. No confundirás la interculturalidad con el foklorismo.

4. Facilitarás una construcción de identidad libre y responsable.

5. Tomarás los aprendizajes como medios al servicio de los fines educativos.

6. Te esforzarás para que todas las actividades de aprendizaje sean significativas para todos, especialmente para los alumnos de los grupos minoritarios.

7. No caerás en la tentación de las agrupaciones homogéneas de alumnos.

8. No colaborarás en la creación ni la consolidación de servicio étnico.

9. Evitarás juicios temerarios sobre las familias de los alumnos

10.Reconocerás tu ignorancia, tus prejuicios y tus estereotipos y la necesidad de una formación permanente y específica.

\section{Mediación e Interculturalidad}

Desde este decálogo deontológico para el docente intercultural se desprende un subcontenido, específicamente importante para el contexto antropológico ecuatoriano: la "mediación intercultural". La interculturalidad como Politica Cultural es una "nueva forma de hacer política" ya que cuestiona los procesos por los cuales y, las formas en las cuales, las relaciones de poder entre el Estado, la cultura predominante y las identidades étnicas se han establecido. De esta forma, la interculturalidad es una estrategia político-cultural, desde sus principios, invocada por parte de los movimientos étnicos, en las negociaciones y resolución de conflictos que este mantiene con el Estado, desempeñando así el rol de ideología-mediadora. En esta actividad de Política Cultural de los movimientos sociales se genera un proceso de transformación social a través de la transformación de la cultura política de la sociedad. Esto en cuanto a la interculturalidad como política cultural. En cuanto a Cultura Política, la interculturalidad es, en cambio, un principio que regula el comportamiento, las normas, actitudes y opiniones de la sociedad. Dagnino, por ejemplo, afirma que "las políticas de identidad incluyen las alianzas y coaliciones que se pueden dar entre las distintas identidades proveyendo de una base para la acción colecti- 
va y permitiendo la producción de una solidaridad social; porque el reconocimiento de identidades y el otorgamiento de derechos no provee, por si mismo, las bases-fundamentos necesarios para construir una nueva solidaridad social" (Dagnino 1998, 49). De tal manera que estas alianzas y coaliciones pueden ser articuladas y sustentadas por los principios de la interculturalidad estableciendo un "código de conducta" a la hora de la praxis del dialogo intercultural; como investigadora, una razón más para seguir definiendo éstos.

Desde esta perspectiva, la interculturalidad debe ser considerada como un principio, un código de comportamiento que sirve como instrumento políticocultural que dirige las relaciones, ya no solo entre el Estado y los movimientos sociales que representan identidades marginalizadas, sino entre ellas también y entre conciudadanos.

Recojo en primer lugar la definición de Desenvolupament Comunitari y Andalucía Acoge "entendemos la Mediación Intercultural como un recurso profesionalizado que pretende contribuir a una mejor comunicación, relación e integración entre personas o grupos presentes en un territorio, y pertenecientes a una o varias culturas" (Desenvolupament Comunitari y Andalucía Acoge 2002, 101). y desde esta concepción los autores identifican tres tipos de mediación intercultural:

- La mediación preventiva: consiste en facilitar la comunicación y la comprensión entre personas con códigos culturales diferentes.

- La mediación rehabilitadora: que interviene en la resolución de conflictos de valores, entre minorías culturales y la sociedad mayoritaria, o en el seno de las propias minorías.

- La mediación creativa: consiste en un proceso de transformación de las normas, o más bien de creación de nuevas normas, nuevas ocasiones basadas en unas nuevas relaciones entre las partes.

\section{Metodología de la interculturalidad}

Para mi visión de la interculturalidad, esta es totalmente hermeneuta en sus métodos. La interculturalidad abre el espacio al diálogo y lo clausura con el consenso. En el proceso intercultural que se lleva del dialogo al consenso hay que exponer, argumentar y escuchar las diferencias. Una vez expuestas las 
diferencias se puede mejorar y desarrollar las articulaciones. En este proceso intercultural del dialogo al consenso la pregunta es ineludible. Esto es lo que hace precisamente la hermenéutica. El proceso es hermenéutico en cuanto está dirigido a desarrollar y mejorar las articulaciones de un significado íntimamente asociado. Y es dialectico en cuanto involucra la yuxtaposición de ideas en conflicto forzando la reconsideración de posiciones previas.

En cuestiones de verdad, la pregunta es primero que el método; y no hay método que enseñe a preguntar. El preguntar no es una técnica que se puede enseñar, nos dice Gadamer. Rafael Flórez Ochoa (2000) lo explica bien:

el arte de preguntar y buscar la verdad es el arte de mantener siempre abierta la orientación hacia las diversas posibilidades; de mantener la pregunta siempre erguida, de seguir preguntando. El arte de preguntar es el arte de pensar, y se llama dialéctica (dialógica) porque su forma natural de realización es la conversación entre dos personas. En este sentido el dialogo es a la investigación pedagógica como el agua para el pez, no por condición sino como oportunidad imprescindible. Llevar una conversación significa mirar juntos en la misma dirección o al menos con la misma intención de formarse conceptos como elaboración común a partir de las opiniones de cada uno, la ventaja de la conversación sobre la rigidez de los tratados, y de los textos es precisamente que el habla se realiza en preguntas y respuestas en el toma y dame de argumentar y del ponerse de acuerdo sobre el sentido cuya elaboración constituye la tarea de arte de preguntar, de pensar, de comprender" (Gadamer 1984).

El hermeneuta no es un espectador desinteresado, despojado de prejuicios intereses y expectativas como se le exige al fenomenólogo para captar la esencia de las cosas o, como se le exige al experimentador positivista de poner entre paréntesis su subjetividad. Por el contrario el hermeneuta activa su experiencia previa, su mundo, su subjetividad su propio horizonte conceptual para poder orientarse hacia el objeto de su indagación para poder hablar con sentido y convertirse en interlocutor del acontecimiento cuyo sentido busca desvelar mediante una especie de "fusión de horizontes", lo que para el discurso interculturalista se entiende por encontrar la "unidad" en la diversidad, el consenso. (Gadamer 1984, en Flórez 2000, 260). 
La reflexión hermeneuta interesa a la interculturalidad en tanto y en cuanto el sujeto interculturalmente competente tampoco se despoja de su identidad y de su bagaje cultural para entender al Otro, al contrario, necesita saber y sentirse bien con sus orígenes para llegar a aceptar al Otro; es en una segunda etapa de este encuentro en el que el sujeto intercultural suspende todo elemento conceptual, procedimental o actitudinal con tintes de estereotipo o prejuicio para iniciar un dialogo, un encuentro de aprendizaje con el Otro.

\section{El indagador hermeneuta como profesor}

El profesor hermeneuta es muy diferente al profesor convencional, pues no parte de la certidumbre, ni de la seguridad del conocimiento en su disciplina para dosificarles "porciones" de verdad a sus alumnos. El hermeneuta enseña desde la duda, desde la pregunta, desde lo que no se sabe a ciencia cierta, desde la incertidumbre, desde la propia ignorancia y la de los alumnos. Desde la actitud de buscar incansablemente y de armar mejor el pensamiento para avanzar por ese camino de nunca acabar que es la vida del espíritu inteligente, que no se cansa de explorar el mundo, que no se estanca que no se paraliza que no se aferra prematuramente. La actitud hermenéutica distingue al indagador en cuanto no busca, no habla ni mira el mundo desde un lugar privilegiado y absoluto como si no tuviera condicionamientos como los demás mortales como si no tuviera su historia ni ataduras sociales y culturales. El hermeneuta cuando enseña sabe que su primera tarea es aclarar e interpretar el fondo histórico social y cultural que siempre lo acompaña a sus espaldas como su sombra que es mejor tematizarlo y entenderlo. El profesor hermeneuta enseña e investiga a la vez. La descripción neutral y objetiva libre de valores y de interpretación subjetivo es un tipo de investigación ya superada y suficientemente criticada nos recuerda Flórez Ochoa (2000).

Toda investigación social es humana, es decir, se diseña y desarrolla desde cierto contexto y horizonte propios del investigador que le permites ver y enfatizar en unas cosas más que en otras; identificar ciertas relaciones como más reveladoras, definir ciertos sentidos como más significativos para él como investigador, para la época, para la comunidad, para las prioridades socioculturales y políticas que están en juego a propósito de la investigación que se realiza y toda investigación es una interpretación y toda interpretación es una valoración cualitativa de la experiencia (Flórez Ochoa, Pedagogía del Conocimiento). El 
profesor hermeneuta no está pendiente de los exámenes ni de las calificaciones ni de la medición de rendimiento académico de los alumnos; cuando el pedagogo hermeneuta evalúa su interpretación del aprendizaje hace una valoración cualitativa del trabajo de los estudiantes. Deja de ser un dictador de clase y se convierte en un ensayador de propuestas de enseñanzas y estrategias autoreguladas para mostrar en la práctica si funcionan o no.

\section{Bibliografía}

ÁLVAREZ Sonia, Evelina Dagnino y Arturo Escobar;

1998 Culture of Politics, Politics of Culture. Re-visioning Latinamerican Social Movements, Westview Press, United States of America.

ANTIKAINEN Ari, Jarno Houtsonen, Jupa Kauppila, Hannu Huoutelin, 1996 Living in a Leaming Society. Falmer Press, Bristol, UK.

CASTELLS, Manuel, Teoría de la ciudad

COLOM Antoni,

2004 Foweraker Joe, Theorizing Social Movements, Pluto Press, 1995, London, UK.

FLORES Ochoa Rafael

2000 Pedagogía del Conocimiento, McGraw Hill, 2da. edición.

GENNARI, Mario

1998 Pedagogía de la Ciudad, Paidos

KANE Liam,

2001 Popular Education and Social Change in Latin America, Russell Press, Nottingham, UK

SÁNCHEZ, Joyce,

2005 www.boletintercultural.blogspot.com. 